\title{
Studies on the Biosynthesis of Asperparaline A: Origin of the Spirosuccinimde Ring System
}

\author{
Chandele R. Gray, ${ }^{a}$ Juan F. Sanz-Cervera, ${ }^{b}$ Louis A. Silks ${ }^{c}$ and Robert M. \\ Williams $^{\text {a* }}$ \\ ${ }^{a}$ Department of Chemistry, Colorado State University, Fort Collins, Colorado 80523 \\ ${ }^{b}$ Departamento de Química Orgánica, Facultad de Química, Universidad de Valencia, Calle Dr. \\ Moliner, 50. \\ E-46100 Burjassot, Spain \\ ${ }^{c}$ NIH Stable Isotope Resource, Los Alamos National Laboratory, Los Alamos, New Mexico 87545 \\ e-mail:rmw@chem.colostate.edu
}

SUPPORTING INFORMATION

\section{Feeding Experiment with $A$. japonicus JV-23:}

Each potato dextrose agar slant was streaked with $A$. japonicus $\mathrm{JV}-23$ spores $(50 \mu \mathrm{L}$ of a $15 \%$ glycerol/water suspension). $500 \mathrm{~mL}$ of potato dextrose agar is prepared by boiling unwashed, cubed russet potatoes $(150 \mathrm{~g})$ in $500 \mathrm{~mL}$ dd water until cooked. Potatoes and broth filtered through cheesecloth and diluted to a volume of $500 \mathrm{~mL}$ as necessary. Broth is then combined with dextrose $(10.0 \mathrm{~g})$ and agar $(7.5 \mathrm{~g})$ and heated gently until all solids dissolve. The slants were then sterilized in an autoclave at $250^{\circ} \mathrm{C}$ for 45 minutes. After inoculation, the slants were incubated in the dark at $25{ }^{\circ} \mathrm{C}$ for 7-10 days.

The spores of two slants were shaken into a flask containing $400 \mathrm{ml}$ sterile potato dextrose broth. One liter potato dextrose broth is prepared by boiling unwashed, cubed russet potatoes $(300 \mathrm{~g})$ in $1 \mathrm{~L}$ dd water until cooked. Potatoes and broth filtered through cheesecloth and diluted to a volume of 1L as necessary. Broth is then combined with dextrose $(20.0 \mathrm{~g})$ and tryptose $(3.0 \mathrm{~g})$ and heated gently until all solids dissolve. The broth was then sterilized in an autoclave at $250^{\circ} \mathrm{C}$ for 45 minutes. The inoculated flasks were incubated in the dark at $25^{\circ} \mathrm{C}$ for 4 days.

The potato dextrose broth was decanted from the flasks leaving a disk of A. japonicus JV-23. A sterile solution of the proposed biosynthetic precursor in trace element solution (see Table for the volume and molarity of each solution) was added by dripping it down the side of the flask and under the mycelia using a sterile syringe. Each labeled compound was added to six flasks. The flasks were left in the incubator another 14 days. The flasks were swirled daily to allow even distribution of the labeled compound.

The aqueous solution containing the precursor was decanted off. 1-2 mL methylene chloride was added to the solution which was then covered and stored at $4{ }^{\circ} \mathrm{C}$. The mycelia of each feeding experiment were combined with the mycelia of the duplicate experiment and pureed with $500 \mathrm{~mL} 1: 1$ $\mathrm{MeOH} / \mathrm{CHCl}_{3}$ in an Oster blender. The contents of the blender were poured into a $2 \mathrm{~L}$ Erlenmeyer flask. The blender was rinsed three times with $1: 1 \mathrm{MeOH} / \mathrm{CHCl}_{3}$ and the suspension of mycelia cells was diluted to a volume of $1.2 \mathrm{~L}$ with $1: 1 \mathrm{MeOH} / \mathrm{CHCl}_{3}$. The mycelia cells were placed in a shaker at room temperature for $24 \mathrm{~h}$.

Table: 


\begin{tabular}{|c|c|c|c|c|}
\hline Proposed Biosynthetic Precursor & $\begin{array}{c}\text { Amount of } \\
\text { Precursor } \\
\text { (mmol) }\end{array}$ & $\begin{array}{l}\text { Molarity of the } \\
\text { Solution }\end{array}$ & $\begin{array}{l}\text { Volume added to } \\
\text { each flask (mL) }\end{array}$ & $\begin{array}{c}\text { Amount of } \\
\text { Asperparaline A } \\
\text { produced (mmol) }\end{array}$ \\
\hline$\left[1,2-{ }^{13} \mathrm{C}_{2}\right]$-acetate & 14.3 & $2.38 \times 10^{-2}$ & 100 & 0.0139 \\
\hline$\left[\right.$ methyl $\left.-{ }^{13} \mathrm{C}\right]$-L-methionine & 0.999 & $1.66 \times 10^{-3}$ & 100 & 0.0147 \\
\hline$\left[1-{ }^{13} \mathrm{C}\right]$-L-isoleucine & 1.01 & $1.68 \times 10^{-3}$ & 100 & 0.00556 \\
\hline$\left[1-{ }^{13} \mathrm{C}\right]$-L-tryptophan & 0.731 & $1.22 \times 10^{-3}$ & 100 & 0.00862 \\
\hline [indole-2- $\left.{ }^{13} \mathrm{C}\right]$-L-tryptophan & 0.591 & $9.84 \times 10^{-4}$ & 100 & 0.00529 \\
\hline$\left[3-{ }^{13} \mathrm{C},{ }^{2} \mathrm{H}_{2}\right]$-L-serine & 1.11 & $1.85 \times 10^{-3}$ & 100 & 0.00390 \\
\hline
\end{tabular}

Celite $(30 \mathrm{~g})$ was added to the flask. The suspension was filtered through Whatman \#2 paper. The filtrate was stored at $4^{\circ} \mathrm{C}$. The residual celite and mycelia was suspended in $1.2 \mathrm{~L} 1: 1$ $\mathrm{MeOH} / \mathrm{CHCl}_{3}$ and shaken at room temperature for an additional $24 \mathrm{~h}$.

The celite and mycelial suspension was filtered through Whatman \#2 paper. The organic solvent from the combined filtrates was concentrated by rotary evaporation. The aqueous solution from the feeding experiment was combined with aqueous residue and the mixture was acidified to $\mathrm{pH} 3 \mathrm{with}$ glacial acetic acid. The acidic solution was filtered through a pad of celite and extracted with ethyl acetate $(400 \mathrm{ml} \times 3)$. The aqueous layer was made basic, $\mathrm{pH} 12$, by the addition of $10 \%$ aqueous $\mathrm{Na}_{2} \mathrm{CO}_{3}$. The aqueous layer was extracted with ethyl acetate $(450 \mathrm{~mL} \times 4)$. The combined organic extracts from the basic extraction were washed with brine $(800 \mathrm{~mL})$, dried $\left(\mathrm{Na}_{2} \mathrm{CO}_{3}\right)$ filtered and concentrated by rotary evaporation. The asperparaline A was purified by successive silica gel chromatography with 9:1 ethyl acetate/methanol and 95:5 chloroform/methanol. (See table for the yield of asperparaline isolated from each experiment.)

\section{Calculation of the percent incorporation using ${ }^{13} \mathrm{C}$ NMR data:}

To interpret the integral results for a feeding experiment the integrals must be normalized to eliminate the effects of the nuclear Overhauser enhancements and different relaxation times that cause the difference in intensities of carbon signals. Since asperparaline has 20 carbon atoms, each signal should be ideally $1 / 20=5 \%$ of the total integral (except for the signal at $53.3 \mathrm{ppm}$ which is the overlapping signal for both $\mathrm{C} 16$ and $\mathrm{C} 20$, and thus should be $10 \%$ of the total integral.) Dividing $5 \%$ by the real percentage of the total integral, calculates the correction factor. Multiplying the integral for the feeding experiment by the correction factor provides a corrected integral that now represents relative ${ }^{13} \mathrm{C}$ abundances that can be directly compared for different positions. To calculate the percentage of the total ${ }^{13} \mathrm{C}$ at each position, divide each corrected integral by the sum of the corrected integrals. The percentage of ${ }^{13} \mathrm{C}$ at each position is determined by multiplying the percentage of the total ${ }^{13} \mathrm{C}$ in the molecule by the average ${ }^{13} \mathrm{C}$ percentage in the whole molecule (obtained from electrospray mass spectral data) by 1200 (as each of 100 molecules of asperparaline contains 20 carbon atoms) for each position. Enrichment is then calculated by subtracting the natural abundance of ${ }^{13} \mathrm{C}$, which is $1.1 \%$, from the percent of ${ }^{13} \mathrm{C}$ at each position. 


\section{Calculation of Percent Incorporation from Mass Spectra Data:}

The percentage of ${ }^{13} \mathrm{C}$-enrichment in the fungal metabolites from isotopically labeled biosynthetic precursors was calculated according to the method of Lambert et al. These calculations are based on the comparison of the mass spectrum of the labeled material to the mass spectrum of the unlabeled material. For these experiments, electrospray mass spectroscopy was used, thus the base peak in the mass spectrum was the $\mathrm{M}+\mathrm{H}$ peak.

\section{Reference:}

(1) J.B. Lambert, H.B. Shurvell, D.A. Lightner, R.G. Cooks, Organic Structural Spectroscopy, Prentice Hall, New Jersey, 1998, pp 447-448. 


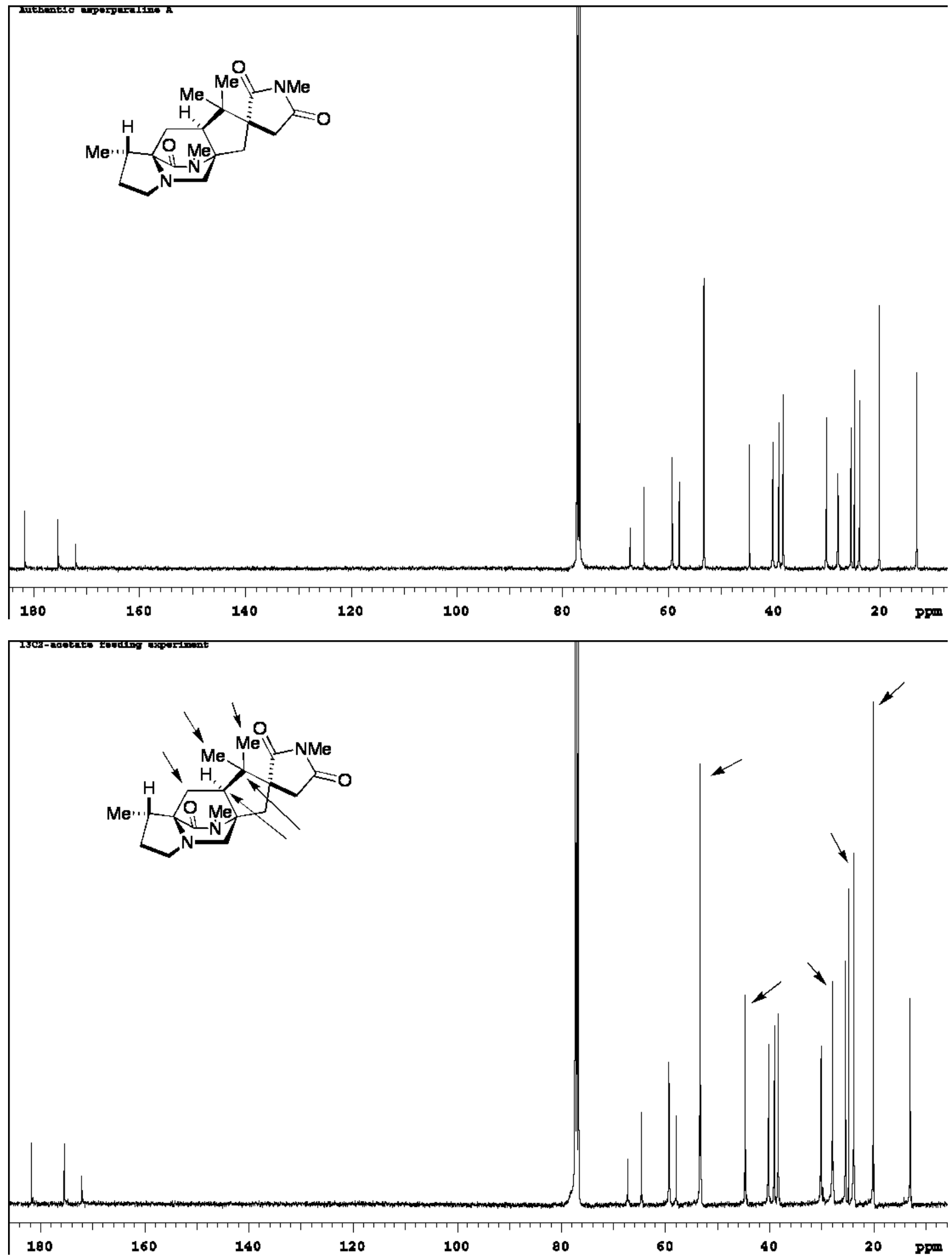



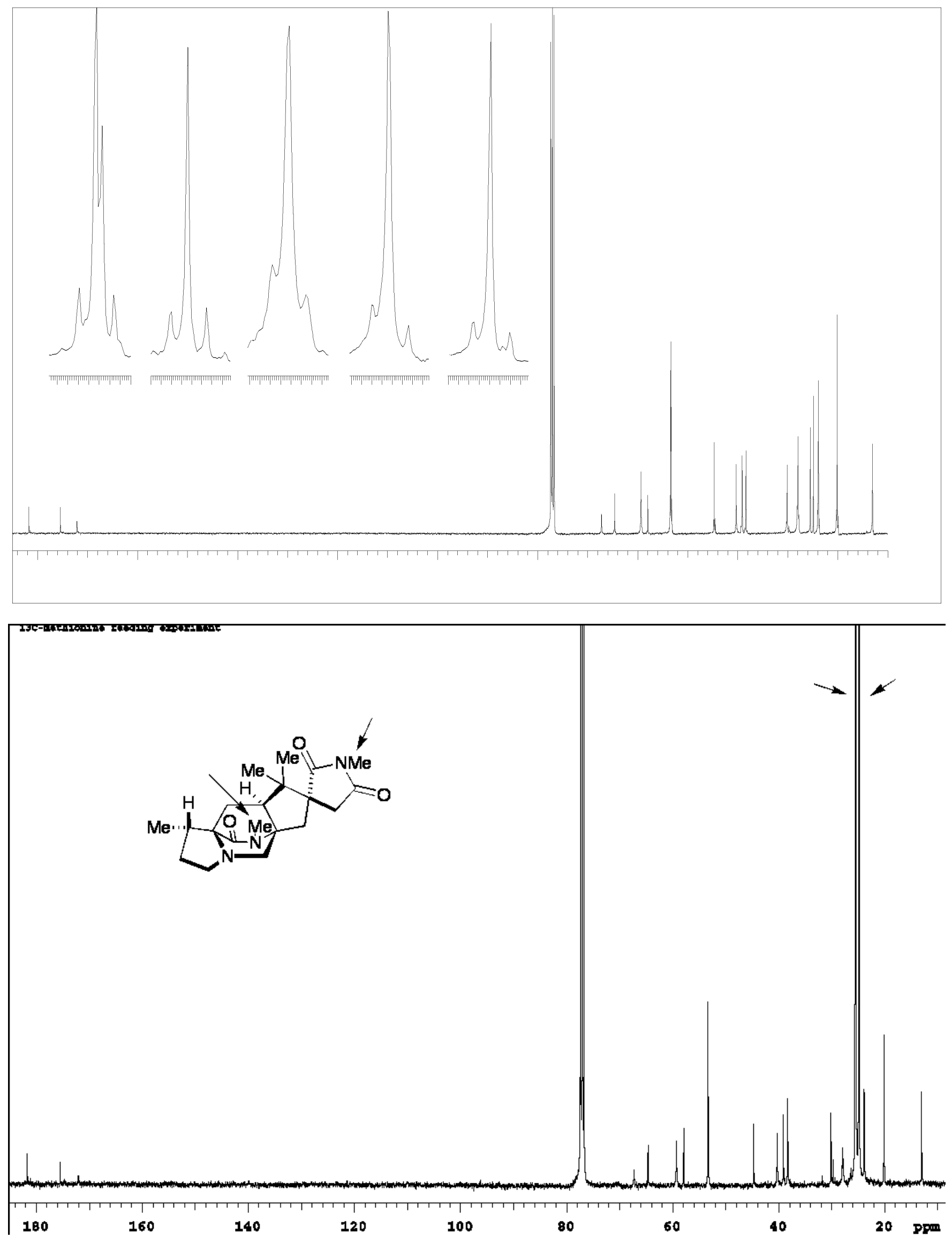

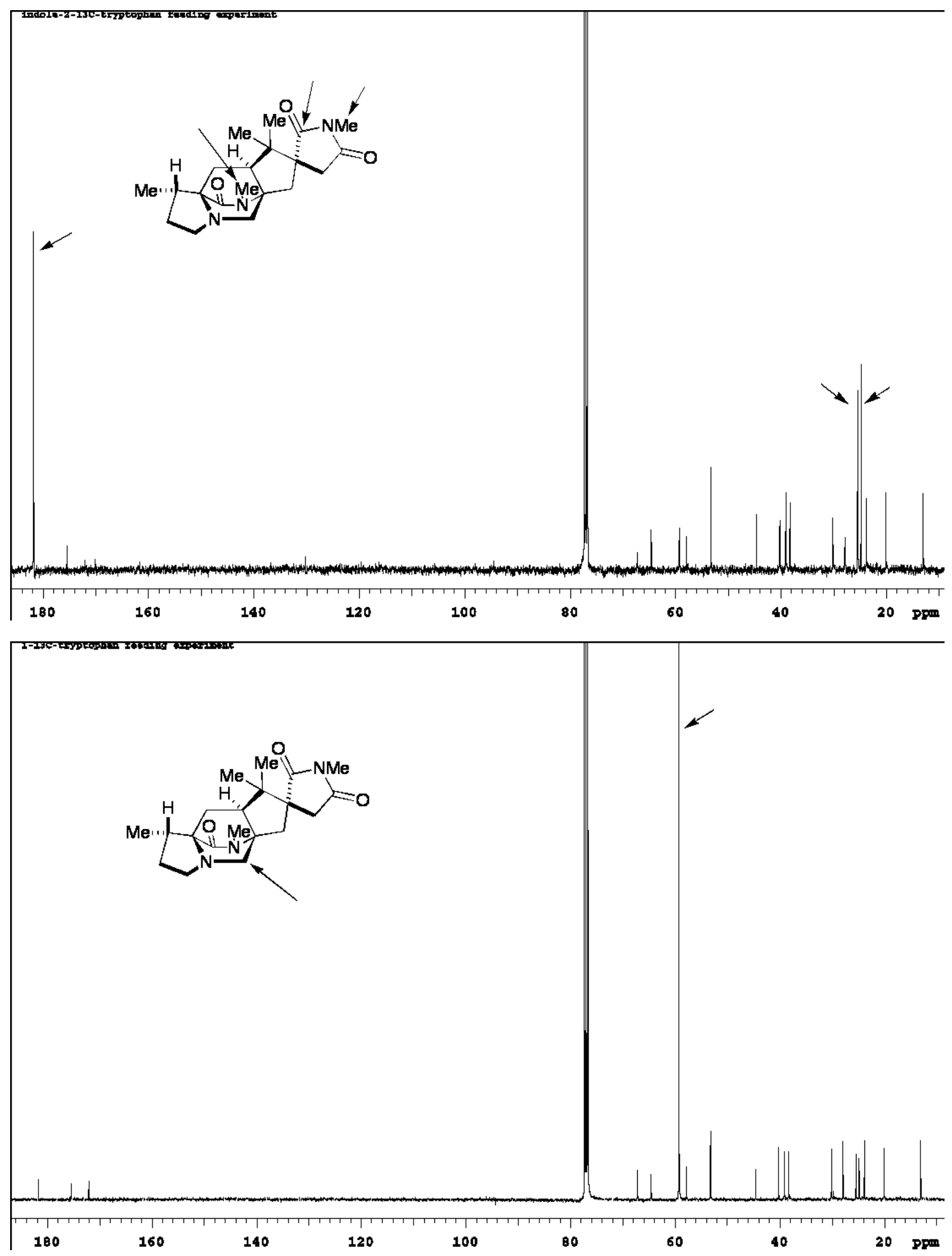
$3-{ }^{13} \mathrm{C}$ Serine feeding experiment

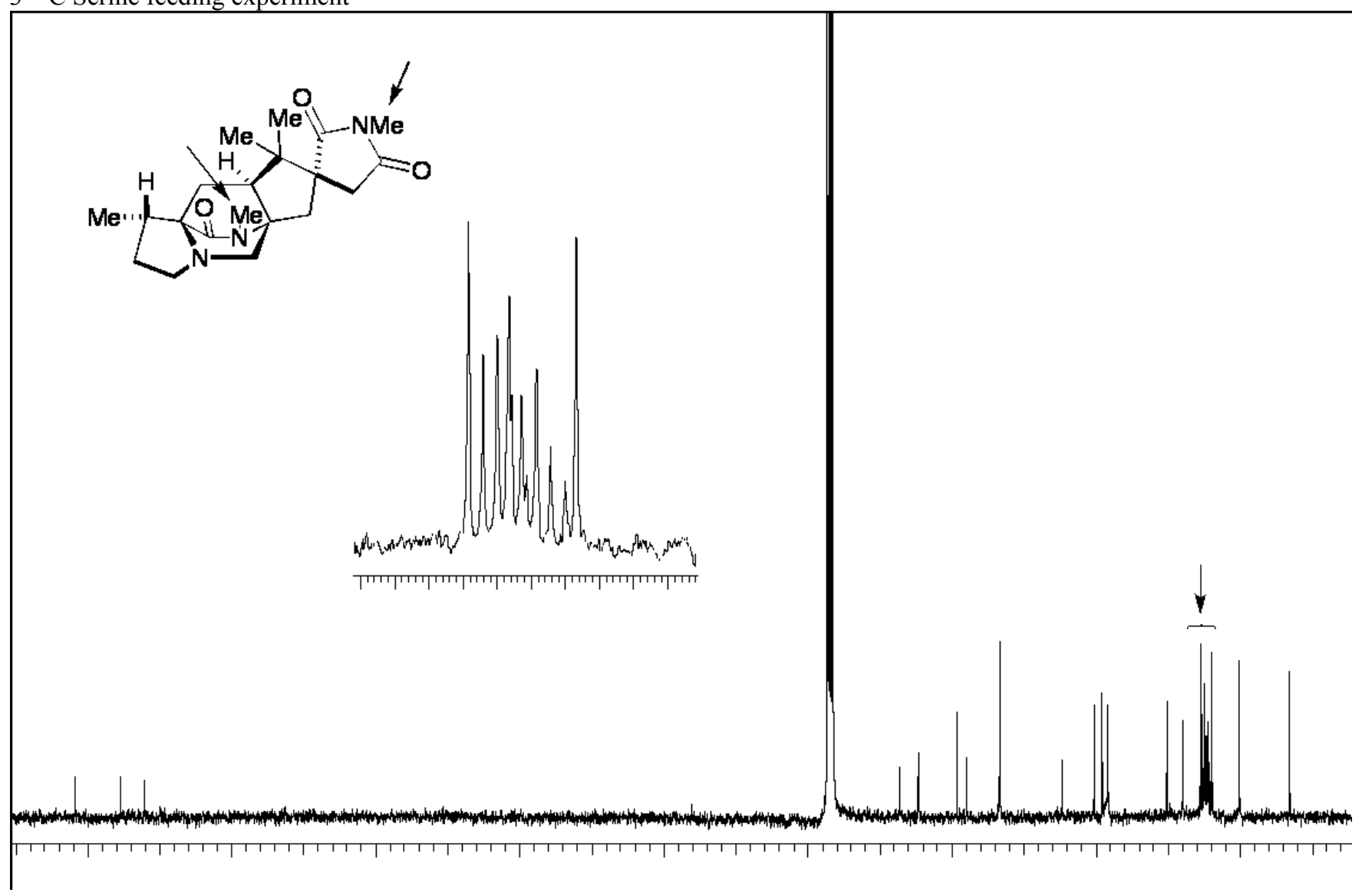

